\title{
Characterization of lumbar angle, pelvic sagittal balance and flexibility in preschoolers
}

\author{
Camila Mayumi Beresoski', Mariana Zingari Camargo², Cláudia Patrícia Cardoso M. Siqueira³, \\ Débora Beckner de Almeida Leitão Prado Vieira ${ }^{4}$, Fabíola Unbehaun Cibinello ${ }^{4}$, Rodrigo Antonio Carvalho Andraus ${ }^{5}$, \\ Dirce Shizuko Fujisawa ${ }^{6}$
}

\begin{abstract}
Introduction: The alignment between anterior superior and inferior posterior iliac spine is related to the lumbar curvature in the sagittal plane. Objective: To characterize the flexibility and angulations of the lumbar spine and the relation with the pelvic tilt in sagittal plane of preschool children. Methods: Participated in the study 138 children with ages ranging from five to six years and enrolled in eight public schools. The evaluation was performed by photogrammetry, pelvic sagittal balance test and limb stretching by fleximeter and Thomas test. Results: There was no difference in the lumbar angle with relation to gender, body mass and age. With regard to pelvic sagittal balance, the majority of preschoolers presented pelvic retroversion (56.6\%). Children with pelvic anteversion (4.3\%) presented a lower lumbar angle, indicating hyperlordosis. Children with pelvic sagittal balance presented better flexibility of the hamstring muscles than those with the pelvis in retroversion and anteversion. Conclusion: Flexibility was greatest in girls and in five-year-old children. The angle of the lumbar was $24.07^{\circ}$. The pelvis was retroversed in most children, differing from expected for the age group. The lowest angle of the lumbar region corresponded to a pelvis in anteroversion and balanced.
\end{abstract}

Keywords: posture, preschool, lumbosacral region, pelvis.

\section{INTRODUCTION}

Lumbar lordosis is the compensatory curvature that directs the center of gravity of the head, neck and torso to the lower limbs, distributing body weight and maintaining the posture. The relationship between pelvic tilt and lumbar lordosis can be observed in orthostatic position. The anterior pelvic tilt provides increased lumbar lordosis. However, ligament and muscle tensions may also affect the curvature of lumbar lordosis. ${ }^{(1)}$

The pelvis presents an important function for postural correction and balance, since it is responsible for supporting the abdomen, connecting the spine to the lower limbs and sustaining body weight and movements of the upper limbs. In addition, the pelvis should be in a neutral position to maintain proper body balance and thus adjust the upper and lower limbs to dynamic positions and provide support for performing activities of daily living.(2) Normal alignment of the pelvis is affected by the contracting forces of the muscles around it, for example, the abdominal and hamstring muscles. ${ }^{(3)}$ When the flexibility of the hamstring muscles is reduced, movement of the pelvis is limited, causing change in the pelvic rhythm.
Preschool children present abdominal protrusion when they are in orthostatism associated with lumbar hyperlordosis. During the growth period, the posture will change and present alignment closer to the adult. (4) $^{(4)}$ The physiological conditions of the pelvis in the child is the neutral position (alignment in the sagittal plane between the anterior superior and posterior inferior iliac spines). When the pelvis presents anterior slope there is an increase of the lumbar lordosis and when the pelvis tilts posteriorly the lumbar lordosis reduces..$^{(5)}$ Lumbar disorder in preschool children may have important consequences on the development of posture and thus into adult life, and an understanding of the relationship between variables may provide grounds for action in prevention during child growth and development. ${ }^{(6)}$

Several ways are recommended to evaluate body posture. Photogrammetry is a useful tool for posture analysis, since it assigns quantitative values to the clinical evaluation, besides being reliable, ${ }^{(7)}$ non-invasive and a low cost method. ${ }^{(8)}$ However, there are few studies that determine normal values for pelvic sagittal alignment in children, due to the different methodologies that are normally used. ${ }^{(9)}$ 
Currently, preschool children remain in the seated position longer, both at school and at home, which can cause postural changes and muscle shortening. Therefore, the objective of this study is to characterize flexibility, lumbar lordosis angulation, and the relationship with pelvic in the sagittal plane in pre-school children enrolled in municipal schools.

\section{METHODS}

This is a cross-sectional study carried out with a convenience sample, consisting of 138 healthy children, aged between five and six years old, from eight municipal schools in different regions of the city. The schools were randomly selected by the Municipal Department of Education.

The exclusion criterion was children who could not remain in orthostatism, with chronic diseases, neurological sequelae or cognitive deficits. The project was approved by the Ethics Committee (N. 240/09) and by the Municipal Department of Education. The parents or guardians of the children signed the free and informed consent form. After the evaluations, the parents or guardians received guidance on the clinical findings and healthy postural habits. Children who presented postural changes and obesity were referred to the Basic Health Unit for follow-up.

Data collection was initiated by the collection of personal data and anthropometric evaluation (body mass and height). The classification of children into eutrophic, overweight and obese was obtained by the $z$ score, according to the recommendations of the World Health Organization (WHO) - Anthro Plus software.

Lumbar angulation in the sagittal plane was evaluated through photogrammetry and the tests: pelvic sagittal balance (PSB), elevation of the lower limb with the fleximeter and Thomas test to assess the flexibility of the iliopsoas muscle. The evaluation of the angle of the lumbar curvature was obtained through photogrammetry using a digital camera (SAMSUNG, 10.2 mega pixel, 1600x1200 pixels), positioned parallel to the ground on a tripod, height of $89 \mathrm{~cm}$ from the ground (perpendicular to the optical center of the evaluated object) ${ }^{(10)}$ and standard distance of 2.5 meters from subject. (11) A reference measure with a size of $10 \mathrm{~cm}$ was attached to the arm of the subject for later calibration of the image. The markers were positioned at anatomical points, with double-sided tape, in: spinous processes of T12, L3 and L5 (procedure performed by single evaluator). The children were positioned at a distance of $20 \mathrm{~cm}$ of the wall, in front of a non-reflective black background. The images were obtained in lateral view with elbow in flexion of $90^{\circ}$, to avoid the interposition of the upper limb in points marked in the column. The captured images were analyzed by the Image $J$ software - free and developed by Wayne Rasband to process and analyze images (National Institute of Mental Health, EUA). For the calculation of the lumbar angle, a line perpendicular to the ground was obtained at a distance of $15 \mathrm{~cm}$ from the subject. The angle of lumbar lordosis was obtained by the intersection of the lines that leave T12 and L5 until their union in the standard vertical line. Thus, the lower the angle of the lumbar curvature, the greater the hyperlordosis and the greater the angle, the greater the tendency to rectify the lumbar lordosis. ${ }^{(12)}$

The PSB was analyzed following the description proposed by Bienfait. ${ }^{(5)}$ For physiology, good static posture presents the upper anterior iliac spine (UAIS) and posterior inferior iliac spine (PIIS) aligned in the horizontal plane. If UAIS and PIIS are in the same plane the pelvis is classified as balanced, if UAIS is below the PIIS the pelvis is in anteversion, and the pelvis in retroversion is when the UAIS is situated above the PIIS in the sagittal plane. Bienfait defines that the position of the pelvis in anteversion follows the position of the lumbar lordosis in hyperlodosis and the retroversion with the rectification of the lumbar lordosis. ${ }^{(5)}$

Hip flexion with knee extension was assessed by the lower limb elevation test. ${ }^{(13)}$ To perform the test, the child was placed in the supine position, the evaluator kept the knee in extension and stabilized the pelvis and lumbar on the surface. The fleximeter (Sunny brand) was placed on the side of the thigh of the evaluated lower limb to avoid some changes during movement at the knee angle. The children performed active movement followed by passive movement performed by the evaluator. In the study, only passive movement measures were considered, due to possible interferences in the active movement performed by the child.

The Thomas test was used to evaluate shortening of the iliopsoas muscle of the contralateral lower limb to the assessed member. The children were placed in dorsal decubitus and the evaluator performed a flexion of the lower limb up to the limit of the subject. The angle formed between the surface and the hip of the contralateral lower limb indicated the presence of iliopsoas muscle shortening. ${ }^{(14)}$

The results were presented as mean and standard deviation or as median and interquartile ranges, according to the normality of the data (Shapiro-Wilk test) and absolute and relative frequencies were used for categorical variables. The comparison between continuous variables was performed using the Kruskal-Wallis test followed by post hoc or Mann-Whitney test. The combination of categorical variables was performed using the chi-square or Fisher's exact test. For analysis of correlation between the continuous variables was used Sperman test. Significance was established in $p<0.05$.

\section{RESULTS}

A total of 138 children (Table 1) were evaluated, and $70.3 \%$ presented eutrophy, $19 \%$ overweight and $10.7 \%$ obesity (Tables 2 and 3).

In the analysis of the lumbar lordosis angle was obtained a median of $24.070\left(20.85^{\circ}-28.18^{\circ}\right)$. There was no statistically significant difference in lumbar lordosis angulation in relation 
to age, gender, body mass and height. As for the PSB, 39.1\% of children presented the balanced pelvis, $56.6 \%$ presented pelvic in retroversion and only $4.3 \%$ presented pelvis in anteversion (Table 3). It was also observed that children who presented the balanced pelvis and pelvis in anteversion had lower angle of lumbar lordosis, $22.7^{\circ}$ e $20.1^{\circ}$ respectively, when compared to the pelvis in retroversion with $25.19^{\circ}(p=0.006$ and $p=0.002)$. Still, regarding PSB, no statistically significant difference was observed with height, body mass, age and gender. However, the six children with pelvis in anteversion were girls.

Regarding flexibility analysis, there was a statistically significant difference between children with balanced pelvis and pelvis in retroversion (Table 4). Difference was also observed when comparing flexibility and gender (Table 4).

Table 1. Characterization of the sample according to age and gender.

\begin{tabular}{ccc}
\hline & $\mathbf{N}$ & $\%$ \\
\hline Age & & \\
5 years & 63 & 45.7 \\
6 years & 75 & 54.3 \\
Gender & & \\
Girl & 65 & 47.1 \\
Boy & 73 & 52.9 \\
\hline
\end{tabular}

Table 2. Anthropometric data of the sample.

\begin{tabular}{lccc}
\hline & \multicolumn{1}{c}{$\mathbf{5}$ years } & $\mathbf{6}$ years & $\mathbf{p}$ \\
\hline Body Mass & $22.4 \mathrm{~kg}(20.0-24.4)$ & $24.6 \mathrm{~kg}(21.50-26,7)$ & $0.014^{*}$ \\
Height & $1.16 \mathrm{~m}(1.12-1.20)$ & $1.19 \mathrm{~m}(1.16$ to 1.24$)$. & $0.001^{*}$ \\
\hline
\end{tabular}

Table 3. Nutritional Classification and Pelvic Sagittal Balance (PSB).

\begin{tabular}{lcc}
\hline & N & \% \\
\hline Classification (Z score) & 97 & 70.3 \\
Eutrophic & 26 & 19.0 \\
Overweight & 15 & 10.7 \\
Obese & & \\
Pelvic Sagittal Balance & 6 & 4.3 \\
Anteversion & 54 & 39.1 \\
Balanced Pelvis & 78 & 56.6 \\
Retroversion &
\end{tabular}

Table 4. Flexibility in relation to pelvic tilt and gender.

\begin{tabular}{lcc}
\hline & Flexibility & $\mathbf{p}$ \\
\hline Pelvic tilt & & \\
Balanced Pelvis & $88.50^{\circ}\left(83.75^{\circ}-96.25^{\circ}\right)$ & $0.003^{*}$ \\
Retroversion & $84^{\circ}\left(74^{\circ}-90.25^{\circ}\right)$ & \\
Gender & \\
Boy & $85^{\circ}\left(75^{\circ}-90^{\circ}\right)$ & \\
Girl & $89^{\circ}\left(82^{\circ}-97^{\circ}\right)$ & $0.006^{*}$ \\
\hline
\end{tabular}

Five-year-old showed greater flexibility $(p=0.037)$ than the six-year-old children. In Thomas test, 102 children (73.9\%) presented the negative test and only 36 children $(26.1 \%)$ presented the positive test. No statistically significant differences were found when the Thomas test results were analyzed with the variables of lumbar angulation, pelvic tilt, gender and $z$ score.

\section{DISCUSSION}

This study aimed to characterize the lumbar lordosis angulations and the relationship with the sagittal plane of pelvic tilt in preschool children. It was observed that there is no significant difference between lumbar lordosis angulation with respect to gender, age and body mass. In a study that evaluated children aged six to eight years using the photogrammetry method, was identified the mean of 25.31 o for the lumbar lordosis angle, similar to the present study. ${ }^{(15)}$

Postural evaluation through photogrammetry is a method that tends to gain space in postural studies rather than purely subjective or clinical appreciation. Santos et al. evaluated the reliability of photogrammetry through the analysis of postural alignment, involving 122 healthy children. ${ }^{(7)}$ The researchers found that this is an adequate and reliable quantitative method and that its application can generate reference parameters for the posture of the child. In addition, studies of Saad et al., ${ }^{(16)}$ Gongora et al. ${ }^{(17)}$ and Lima et al. ${ }^{(18)}$ also presented good reliability for photogrammetry. Other studies show that the software also has good reliability. ${ }^{(19,20)}$ The study of Giglio and Volpon ${ }^{(21)}$ analyzed the curvature of the lumbar by a validated instrument and found a linear increase of the angle according to the age: from 220 in children with five years of age to $32 \circ$ in subject with twenty years. Araujo and Fazzi ${ }^{(22)}$ also found in their study the positive correlation between age and lumbar angle. The present study did not find a significant difference between age and lumbar angle, probably by the restricted age.

The study also found no association between lumbar curvature and body mass, disagreeing with other studies ${ }^{(23,24)}$, which showed that obese children had a higher incidence of lumbar hyperlordosis when compared with weight considered normal for age. This may be justified by the fact that most children are with appropriate weight for the age, with only $30 \%$ of the sample being overweight. There was also no difference in lumbar curvature compared to the Thomas test, which is widely used to evaluate iliopsoas muscle shortening. (25) Biomechanically, the positive test may be related to the presence of lumbar hyperlordosis. ${ }^{(26)}$

Regarding the positioning of the pelvis in the sagittal plane, only 54 pre-schoolers had a balanced pelvis, with the majority presenting pelvis in retroversion. Penha et al. evaluated 132 children between seven and ten years of age and observed that the anteversion was among the postural deviations found. ${ }^{(27)}$ The retroversion is explained by the 
sitting posture, in which the support of the body on the chair is performed on the back and sacrum, leading the pelvis to a retroversion and rectification of the lumbar curvature. (28) Such situation can lead to the development of muscular shortenings and compensatory mechanisms. ${ }^{(29)}$ There are no parameters of normality for pelvic classification in anteversion or retroversion for the age group studied for comparison purposes. However, a correlation was observed between the position of the pelvis in the sagittal plane and the lumbar curvature, in which the lowest lumbar angle was corresponding to a pelvis in anteversion and balanced respectively. Other studies also show a strong correlation between lumbar lordosis and pelvic positioning. ${ }^{(30,31)}$ However, the association between pelvic positioning and the variables age, gender, body mass and Thomas test was not observed.

Finally, with regard to flexibility, girls obtained better results than boys, corroborating with other studies. ${ }^{(32,33)}$ In addition, five-year-olds were more flexible than six-year-olds children, agreeing with the study of Murray et al ${ }^{(34)}$, which describes that children have inherently greater range of motion than adults. Significant difference was found between flexibility and pelvic positioning, children with balanced pelvis were more flexible than children with pelvis in retroversion.

Thus, the study did not detect changes in lumbar lordosis angulation, especially when related to age, gender and body mass. However, the relationship between lumbar lordosis and pelvic balance can be observed. In addition, difference in flexibility was presented among children with respect to gender and age. High index of pelvic in retroversion was identified in the sample, which may be related to the prolonged time in improperly seated posture, which can also generate muscular retractions, mainly of the hamstrings muscles.

Thus, the results of the study point to changes in pelvic positioning, which may lead to early postural changes and may have repercussions in adult life. Therefore, educational programs should be adopted early in schools, including parents, teachers and children through guidelines for the development of healthy postural habits.

\section{ACKNOWLEDGMENT}

We are grateful for the willingness and collaboration of the team (teachers and students) of the UEL/UNOPAR in Rehabilitation Sciences Program.

\section{AUTHOR'S CONTRIBUTION}

$\mathrm{CMB}$ - the conception and design of the study, acquisition of data, analysis and interpretation of data; $\mathrm{MZC}$ - the conception and design of the study, acquisition of data, analysis and interpretation of data; CPCMS - drafting the article or revising it critically for important intellectual content; DBALPV - drafting the article or revising it critically for important intellectual content and acquisition of data; FUC - acquisition of data; RACA - drafting the article or revising it critically for important intellectual content; DSF - the conception and design of the study, acquisition of data, analysis and interpretation of data.

\section{CONFLICTS OF INTEREST}

The authors declare no have conflict of interest.

\section{AUTHOR DETAILS}

${ }^{1}$ Physiotherapist, Londrina State University (UEL), Londrina (PR), Brazil. ${ }^{2} \mathrm{MSc}$, Scholarship of the Social Demand Program (DS) - CAPES, Londrina State University (UEL), Londrina (PR), Brazil. ${ }^{3} \mathrm{PhD}$, Londrina State University (UEL), Londrina (PR), Brazil. ${ }^{4} \mathrm{MSc}$, Londrina State University (UEL), Londrina (PR), Brazil. ${ }^{5}$ PhD, University of Northern Paraná (UNOPAR), Londrina (PR), Brazil.

\section{REFERENCES}

1. Lee JH, Yoo WG, Hwang-bo G. The Immediate Effect of Anterior Pelvic Tilt Taping on Pelvic Inclination. J. Phys. Ther. Sci. 2011;23(2):201-203.

2. Park G, Ju SB, Jang HJ. The effect of pelvic adjustment on the stability of elderly men. J. Phys. Ther. Sci. 2011;23(6):937-939.

3. Jang J, Koh E, Han D. The effectiveness of passive knee extension exercise in the sitting position on stretching of the hamstring muscles of patients with lower back pain. J. Phys. Ther. Sci. 2013;25(4):501-504.

4. Bricot B. Posturologia. Editora Ícone, 2º edição, São Paulo- SP. 2001.

5. Bienfait M. Os desequilíbrio estáticos: fisiologia, patologia e tratamento fisioterápico. Editora Summus, edição, São Paulo- SP. 1995.

6. Vitta A, Martinez MG, Piza NT, Simeão SFAP, Ferreira NP. Prevalência e fatores associados à dor lombar em escolares. Cadernos de Saúde Pública. 2011;27(8):1520-1528.

7. Santos MM, Silva MPC, Sanada LS, Alves CRJ. Análise postural fotogramétrica de crianças saudáveis de 7 a 10 anos: confiabilidade interexaminadores. Rev Bras Fisioter. 2009;13(4):350-5.

8. Dunk NM, Lalonde J, Callaghan PJ. Implications for the use of postural analysis as a clinical diagnostic tool: reliability of quantifying upright standing spinal postures from photographic images. Journal of Manipulative and Physiological Therapeutics. 2005;28(6):386- 92.

9. Vrtovec T, Janssen MM, Likar B, Castelein RM, Viergever MA, Pernus F. A review of methods for evaluating the quantitative parameters of sagittal pelvic alignment. Spine. 2012;12(5):433-46.

10. Paul A, Douwes MJ. Two - dimensional photographic posture recording and description: a validity study. Applied Ergonomics. 1993;24(2):83-90.

11. Codarin GF, Felicio LR, Coelho DM, Oliveira AS. Análise das distorções em leituras angulares de imagens fotográficas. Rev. Bras. Fisioter. 2012;16(4):309-313.

12. Iunes DH, Castro FA, Salgado HS, Moura IC, Oliveira AS, Bevilaqua-Grossi D. Confiabilidade intra e interexaminadores e repetibilidade da avaliação postural pela fotogrametria. Rev Bras Fisioter. 2005;9(3):327-334.

13. Monteiro GA. Avaliação da Flexibilidade Manual de Utilização do Flexímetro Sanny. 1a Ed.2000.

14. Hoppenfeld S. Propedêutica ortopédica, coluna e extremidades. Rio de Janeiro, editora Atheneu. 2006.

15. Pagnussat AS, Paganotto KM. Caracterização da curvatura lombar em escolares na fase do desenvolvimento estrutural. Fisioterapia e Movimento. 2008;21(1):39-46.

16. Saad KR, Colombo AS, Ribeiro AP, João SMA. Reliability of photogrammetry in the evaluation of the postural aspects of individuals with structural scoliosis. Journal of Bodywork \& Movement Therapies. 2012;16(2):210-6.

17. Gongora H, Romanatti SV, Neto RBD, Santos GML. Índice de confiabilidade intra e interexaminadores da análise do ângulo poplíteo através da biofotogrametria. Revista Ciência \& Saúde. 2009; p. 46.

18. Lima LCO, Baraúna MA, Sologuren MJJ, Canto RST, Gastaldi AC. Postural alterations in children with mouth breathing assessed by computerized biophotogrammetry. J Appl Oral Sci. 2004;12(3):232-7. 
19. Santos JDM, Oliveira MA, Silveira NJF, Carvalho SS, Oliveira AG. Confiabilidade inter e intraexaminadores nas mensurações angulares por fotogrametria digital e goniometria. Fisioterapia e movimento. 2011;24(3):389-400.

20. Fortin M, Battié MC. Quantitative Paraspinal Muscle Measurements: Inter-Software Reliability and Agreement Using OsiriX and ImageJ. Physical Therapy. 2012;92:853-864.

21. Giglio CA, Volpon JB. Development and evaluation of thoracic kyphosis and lumbar lordosis during growth. Journal of Children's Orthopaedics. 2007;1(3):187-193.

22. Araújo FRC, Fazzi A. Valor do ângulo da lordose lombar e do ângulo lombossacro na criança. Revista Brasileira de Ortopedia. 1988;23(9):265271.

23. Kussuki MOM, João SMA, Cunha AP. Caracterização postural da coluna de crianças obesas de 7 a 10 anos. Fisioterapia em Movimento. 2007;20(1):77-84.

24. Siqueira GR, Silva GAP. Alterações posturais da coluna e instabilidade lombar no indivíduo obeso: uma revisão de literatura. Fisioterapia e movimento. 2011;24(3):557-566.

25. Polesello G, Ono N, Honda E, Aristide RSA, Stewien ETM, Gomes FM, Guedes A. O teste de Thomas para cálculo da posição de flexão do quadril no plano sagital nas artrodeses. Revista Brasileira de Ortopedia. 2001;36(5):155-160.

26. Rolf IP. A integração das estruturas humanas. São Paulo: Martins Fontes, 1990.
27. Penha PJ, João SMA, Casarotto RA, Amino CJ, Penteado DC. Postural assessment of girls between 7 and 10 years of age. Clinics. 2005;60(1):916.

28. Kapanji Al. Fisiologia Articular Esquemas comentados de mecânica humana volume III, Editorial Medica Panamericana Maloine Pinheiros São Paulo, 2000.

29. Bruschini S, Nery CA. Aspectos ortopédicos da obesidade na infância e adolescência. In: Fisberg M. Obesidade na infância e adolescência. São Paulo: Fundação Editorial BYK, p. 105-25. 1995

30. Jackson RP, Kanemura T, Kawakami N, Hales C. Spine Lumbopelvic lordosis and pelvic balance on repeated standing lateral radiographs of adult volunteers and untreated patients with constant low back pain. Spine. 2000;25(5):575-86.

31. Guigui P, Levassor N, Rillardon L, Wodecki P, Cardinne L. Physiological value of pelvic and spinal parameters of sagital balance: analysis of 250 healthy volunteers. Revuede Chirurgie Orthopédique et Réparatrice de I’Appareil Moteur. 2003;89(6):496-506.

32. Rassilan EA, Guerra TC. Evolução da flexibilidade em crianças de 7 a 14 anos de idade de uma escola particular do município de Timóteo-MG. Movimentum-Revista Digital de Educação Física. 2006;1:1-13.

33. Penha PJ, João SMA. Avaliação da flexibilidade muscular entre meninos e meninas de 7 e 8 anos. Fisioterapia e Pesquisa. 2008;15(4):387-91.

34. Murray KJ, Woo P. Benign joint hypermobility in childhood Editorials. Rheumatology. 2001;40:489-491. 